\title{
Different type 2 diabetes risk assessments predict dissimilar numbers at risk: a cross-sectional analysis of diabetes risk-assessment tools
}

\author{
Akter $\mathrm{N}^{\mathrm{a}}$
}

\begin{abstract}
Background: Use of a validated risk-assessment tool to identify individuals at high risk of developing type 2 diabetes is currently recommended. It is under-reported, however, whether a different risk tool alters the predicted risk of an individual. This study explored any differences between two commonly used validated risk-assessment tools for type 2 diabetes.

Methods: This is a cross-sectional study conducted between July 2018 and June 2019 in the medicine outpatient department of a tertiary care hospital in Dhaka, Bangladesh. Total 518 subjects, aged ranging from 22 to 68 years was included in the study. Randomly sampled non-diabetic subjects, and those who had previous history of high blood glucose during pregnancy or other health examination (i.e. impaired fasting glucose, impaired glucose tolerance or gestational diabetes mellitus) were included for the study. With written informed consent, both the Indian Diabetes Risk Score (IDRS) and the Finnish Diabetes Risk Score (FINDRISC) questionnaire were used to collect the data including demographic characteristics and different risk factors of an individual subject, and to calculate total risk score for predictors the risk of developing T2DM within 10 years.

Results: Among 518 subjects, 48.1\% were male and 51.9\% were female. Differences between the risk-assessment tools were apparent following cross-sectional analysis of individuals. IDRS (Indian Diabetes Risk Score) categorized $37.8 \%$ (male vs. female: $14.8 \%$ vs. 23.0\%) of individuals at high risk. Whereas, $8.3 \%$ (male vs. female: $1.9 \%$ vs. 6.4\%) were at high risk according to FINDRISC (Finish Diabetes Risk Score) system.

Conclusions: The results indicate that the prevalence of participants at risk for developing type 2 diabetes varies considerably according to the scoring system used. To adequately prevent type 2 diabetes, risk scoring systems must be validated for each population considered.
\end{abstract}

Keywords: Type 2 diabetes mellitus, risk assessment score, Indian Diabetes Risk Score (IDRS), Finnish Diabetes Risk Score (FINDRISC).

(BIRDEM Med J 2020; 10(3): 159-167)

\section{Introduction}

Type 2 diabetes mellitus (T2DM) is a progressive disease with increasing prevalence. This disease remains asymptomatic for years, being discovered only at a stage with preexisting complications. ${ }^{1}$ The prevalence of diabetes is increasing in Bangladesh in both urban and

\section{Author information}

a. Nazma Akter, Assistant Professor (Endocrinology \& Metabolism), Department of Medicine, MARKS Medical College \& Hospital, Dhaka, Bangladesh.

Address of correspondence: Nazma Akter, Assistant Professor (Endocrinology \& Metabolism), Department of Medicine, MARKS Medical College \& Hospital, Dhaka, Bangladesh. Email: nazma_aktar_endo@yahoo.com

Received: October 22, 2019

Accepted: June 30, 2020 rural areas. A recent scoping review (1994-2013) ${ }^{2}$ revealed that the prevalence of type 2 diabetes varied from $4.5 \%$ to $35.0 \%$ in Bangladesh. It increases healthcare use and expenditure and imposes a huge economic burden on the healthcare systems. The International Diabetes Federation estimated ${ }^{3} 8.4$ million people with diabetes in Bangladesh and 4.7 million people with undetected diabetes. This number is estimated to double by 2045 .

Recent studies ${ }^{4}$ have shown that lifestyle or medication intervention could prevent the incidence of type 2 diabetes. Hence, screening tools are needed to identify participants with undiagnosed diabetes or those who are at risk for developing diabetes in the future. For this purpose, numerous risk scores recently have been 
proposed. ${ }^{5-8}$ Participants at high risk of developing type 2 diabetes, according to the risk score threshold, are thus amenable to preventive measures.

A good diabetes risk score ideally should be easily completed by the physician and rely on easily and routinely accessible clinical and biological parameters. Moreover, the risk score has to be accurate enough to provide targeted warnings for the patients. Some scores have been validated in selected populations $7-8$, prompting their use in other countries. ${ }^{9,} 10$ Nevertheless, recent studies ${ }^{11}$ have shown that risk scores that are developed in the same country can lead to different results. Likewise, one equation validated in one country might not provide adequate estimates in another. ${ }^{12}$

The current study aimed to compare the results of scores that estimate the risk of developing type 2 diabetes using risk assessment tools of Indian Diabetes Risk Score (IDRS) and Finish Diabetes Risk Score (FINDRISC).

\section{Methods}

This was a single-center, cross-sectional study conducted between July 2018 and June 2019 in the outpatient department (OPD) of medicine, MARKS Medical College \& Hospital, a tertiary care hospital in Dhaka, Bangladesh. Total 518 subjects, aged ranging from 22 to 68 years was included in the current study. Randomly sampled non- diabetic subjects and those who had previous history of high blood glucose during pregnancy or other health examination (i.e. impaired fasting glucose, impaired glucose tolerance or gestational diabetes mellitus) were included. Individuals with an apparent communicative, cognitive impairment or physical disability were excluded from the study. The risk of developing type 2 diabetes of an individual subject was assessed using two different risk scores, including clinical data. With written informed consent, the Indian Diabetes Risk Score (IDRS) and the Finnish Diabetes Risk Score (FINDRISC) questionnaire were used to collect the data including demographic characteristics and different risk factors, and to calculate total risk score for predictors the risk of developing T2DM within 10 years.

\section{Risk assessment scores}

We performed a Pub Med search and selected risk scores for their relative novelty and their applicability to the Bangladeshi population. Various risk factors of T2DM were reviewed from the literature like sex, age at diagnosis of DM, family history of diabetes, diet and exercise, smoking, hypertension, body mass index (BMI), weight, waist circumference (WC), gestational diabetes, and polycystic ovarian syndrome. ${ }^{13}$ Various risk-assessment scoring systems were reviewed like American Diabetes Association, ${ }^{14}$ Rotterdam, ${ }^{15}$ Cambridge, ${ }^{16}$ Finnish, ${ }^{17}$ Danish, ${ }^{18}$ Indian, ${ }^{19}$ Thai, ${ }^{20}$ Omani, ${ }^{21}$ Kuwaiti, ${ }^{22}$ Australian T2DM risk-assessment tool and Trinidad Risk Assessment Questionnaire-5 (TRAQ-5). ${ }^{23}$

In Bangladesh, still we do not have any diabetes risk assessment scoring system of our own. After review of literature regarding risk factors of developing diabetes and some well validated risk assessment scoring systems for DM of different countries we found the risk assessment tools of Indian diabetes Risk Score (IDRS) 19 and Finnish Diabetes Risk Score (FINDRISC) ${ }^{17}$ to calculate diabetes risk score was more useful for the Bangladeshi adults. The Finnish Diabetes Risk Score (FINDRISC) developed in 2001 and tested for validity and reliability on Finnish population and in different countries. ${ }^{17,24-28}$ The IDRS has a sensitivity of $72.5 \%$ and specificity of $60.1 \%$ and is derived based on the largest population based study on diabetes in India. It has shown to be a highly cost effective way of testing for diabetes in a resource poor setting like India ${ }^{29}$, which has more similar socio-demographic features like Bangladesh.

\section{Methods of calculation of risk score}

Anthropometric measurements of height and weight were measured by a reliable height scale and weighing scale, respectively. BMI [weight in kilograms/square of height in meters $\left(\mathrm{kg} / \mathrm{m}^{2}\right)$ ] was calculated. Hypertension was defined as a systolic blood pressure $\geq 140 \mathrm{mmHg}$ and/or diastolic blood pressure $\geq 90$ $\mathrm{mmHg}$, or in case of use of anti-hypertensive medications ${ }^{14}$. Blood pressure was measured by a manual sphygmomanometer in standard conditions (measured 2 times after a 5-min rest between each measurement). ${ }^{30}$ Waist circumference was measured in a horizontal plane, midway between the inferior margin of the ribs and the superior border of the iliac crest using a reliable measuring inch tape. All the participants were assessed with IDRS, and FINDRISC score systems.

\section{FINDRISC system}

The FINDRISC ${ }^{17}$ had eight risk factors to detect a diabetes risk in a 10-year period based on age, (Less than 45 years: 0 point; $45-50$ years: 2 points ; 55-64 years: 3 points; over 64 years : 4 points), body mass 
index ( lower than $25 \mathrm{~kg} / \mathrm{m}^{2}: 0$ point; $25-30 \mathrm{~kg} / \mathrm{m}^{2}: 1$ point; higher than $30 \mathrm{~kg} / \mathrm{m}^{2}: 3$ points), waist circumference [ Men ( less than $94 \mathrm{~cm}: 0$ point; $94-102$ $\mathrm{cm}: 3$ points; more than $102 \mathrm{~cm}: 4$ points); Women (less than $80 \mathrm{~cm}: 0$ point; $80-88 \mathrm{~cm}: 3$ points; more than 88 $\mathrm{cm}: 4$ points)], at least 30 minutes of physical activity at home or during leisure time ( Yes: 0 point; No: 2 points), eat vegetables, fruit or berries (everyday: 0 point; not every day: 1 point), ever taken antihypertensive medication regularly ( No: 0 point; Yes: 2 points), ever been found to have high blood glucose [ e.g. in a health examination, during illness, during pregnancy] ( No: 0 point; Yes: 5 points), family history of diabetes [No: 0 point; Yes ( grand parent, uncle, aunt, or first cousin) : 3 points; Yes ( parents, brother, sister or own child) : 5 points]. It demonstrates the probability of developing T2DM and the risk score is categorized as $<7$ : low (estimated 1 in 100 will develop DM), 7-11: slightly elevated (estimated 1 in 25 will develop DM), 12-14: moderate (estimated 1 in 6 will develop DM), 15-20: high (estimated 1 in 3 will develop DM) and $>20$ : very high (estimated 1 in 2 will develop DM).

\section{IDRS system}

The IDRS system ${ }^{31}$ has four risk factors to detect a diabetes risk based on age (Less than 35 years: 0 point; 35-49 years: 20 points ; $\geq 50$ years: 30 points), waist circumference [waist $<80 \mathrm{~cm}$ (female), $<90 \mathrm{~cm}$ ( male): 0 point; waist $\geq 80-89 \mathrm{~cm}$ (female), $\geq 90-99 \mathrm{~cm}$ (male): 10 points; waist $\geq 90 \mathrm{~cm}$ (female), $\geq 100 \mathrm{~cm}$ ( male): 20 points], physical activity (regular vigorous exercise or strenuous activities at home or work : 0 points; regular moderate physical activity at home or work : 10 points; regular mild exercise or physical activity at home or work : 20 points; No exercise and/ or sedentary activities at home or work : 30 points;), family history of diabetes (No diabetes in parents: 0 point; One parent is diabetic : 10 points; Both parents are diabetic : 20 points). Subjects with an IDRS of $<30$ was categorized as low risk, $30-50$ as moderate risk and those with $\geq 60$ as high risk for diabetes ${ }^{31-33}$.

\section{Statistical analysis}

Data were analyzed with Statistical Package for Social Science (SPSS) software version 16. The means and standard deviations were used to describe continuous data. For categorical data, frequencies and percentages were estimated. Among the basic characteristics of the study subjects, the continuous variables were compared with each other using the ANOVA test. Categorical variables were compared with each other using the chisquare test. $P$ value $<0.05$ was considered as significant.

\section{Results \\ Baseline characteristics}

Among study population, $48.1 \%$ were male and $51.9 \%$ were female. The mean $( \pm \mathrm{SD})$ age of the study subjects was $38.42 \pm 1.12$ years. Maximum age was 68 years and minimum was 22 years. The mean $( \pm \mathrm{SD})$ height (meter) and weight $(\mathrm{kg})$ were higher in male subjects than female subjects (male vs. female: $1.65 \pm 0.08$ vs. $1.56 \pm 0.06$ and $71.27 \pm 1.22$ vs. $61.67 \pm 1.0$ respectively); [p<0.001]. Average BMI $\left(\mathrm{kg} / \mathrm{m}^{2}\right)$ was $25.79 \pm 3.90$ in male subjects and $24.90 \pm 3.46$ (Mean \pm SD) in female subjects; $[\mathrm{p}<0.05]$. And average $(\mathrm{Mean} \pm \mathrm{SD})$ waist circumference (cm) was $85.99 \pm 8.52$ in male and $84.55 \pm 8.16$ in female subjects $[\mathrm{p}=0.05]$. The mean $( \pm \mathrm{SD})$ blood pressure $(\mathrm{mm}$ of $\mathrm{Hg}$ ) of the study subjects were SBP: $115.22 \pm 1.37$ vs. $117.55 \pm 1.47$ (male vs. female) and DBP: 77.14 \pm 8.67 vs. $77.10 \pm 8.40$ (male vs. female). (Table I)

Table I Comparison of clinical-demographic features, IDRS \& FINDRISC among subjects $(\mathrm{N}=518)$

\begin{tabular}{lcccccc}
$\begin{array}{l}\text { Demographic Features } \\
\text { \& Risk Scores }\end{array}$ & $\begin{array}{c}\text { Male } \\
(\text { Mean } \pm \text { SD })\end{array}$ & $\begin{array}{c}\text { Female } \\
(\text { Mean } \pm \text { SD })\end{array}$ & $\begin{array}{c}\text { Total } \\
(\text { Mean } \pm \text { SD })\end{array}$ & F Value & df & P value \\
\hline Age $(\mathrm{yrs})$ & $38.06 \pm 1.15$ & $38.75 \pm 1.10$ & $38.42 \pm 1.12$ & 0.47 & 1 & 0.490 \\
Height $(\mathrm{m})$ & $1.65 \pm 0.08$ & $1.56 \pm 0.06$ & $1.61 \pm 0.08$ & 169.50 & 1 & $<0.001$ \\
Weight $(\mathrm{kg})$ & $71.27 \pm 1.22$ & $61.67 \pm 1.00$ & $60.29 \pm 1.21$ & 95.56 & 1 & $<0.001$ \\
WC $(\mathrm{cm})$ & $85.99 \pm 8.52$ & $84.55 \pm 8.16$ & $85.24 \pm 8.36$ & 3.84 & 1 & 0.050 \\
BMI $\left(\mathrm{kg} / \mathrm{m}^{2}\right)$ & $25.79 \pm 3.90$ & $24.90 \pm 3.46$ & $25.33 \pm 3.70$ & 7.68 & 1 & 0.006 \\
SBP $(\mathrm{mm} \mathrm{Hg})$ & $115.22 \pm 1.37$ & $117.55 \pm 1.47$ & $116.43 \pm 1.43$ & 699.33 & 1 & 0.065 \\
DBP $(\mathrm{mm} \mathrm{Hg})$ & $77.14 \pm 8.67$ & $77.10 \pm 8.40$ & $77.12 \pm 8.52$ & 0.30 & 1 & 0.949 \\
IDRS & $45.50 \pm 17.05$ & $52.23 \pm 19.26$ & $48.99 \pm 18.52$ & 17.60 & 1 & $<0.001$ \\
FINDRISC & $7.33 \pm 4.31$ & $8.86 \pm 5.22$ & $8.12 \pm 4.86$ & 12.99 & 1 & $<0.001$ \\
\hline
\end{tabular}

WC: Waist Circumference, BMI: Body Mass Index, SBP: Systolic Blood Pressure, DBP: Diastolic Blood Pressure, IDRS: Indian Diabetes Risk Score, FINDRISC: Finish Diabetes Risk Score, ANOVA: Analysis of Variance 


\section{Risk assessment factors of IDRS}

According to IDRS tool, most of the subjects were from $<35$ years age group (male vs. female: $23.9 \%$ vs. $22.0 \%$ ) $[\mathrm{p}=0.12]$. On the basis of waist circumference categories, $16.6 \%$ of female subjects had waist circumference $\geq 90$ $\mathrm{cm}$. But only $5.2 \%$ of male subjects had waist circumference $\geq 100 \mathrm{~cm}[\mathrm{p}<0.001]$. According to physical activity categories, only $19.3 \%$ of male and $24.3 \%$ of female subjects do regular mild exercise or physical activity at home or work place $[\mathrm{p}=0.19]$. In context of family history, $30.5 \%$ of subjects had one diabetic parent and $19.3 \%$ had both diabetic parent $[\mathrm{p}=0.52]$ (Tables II and III).

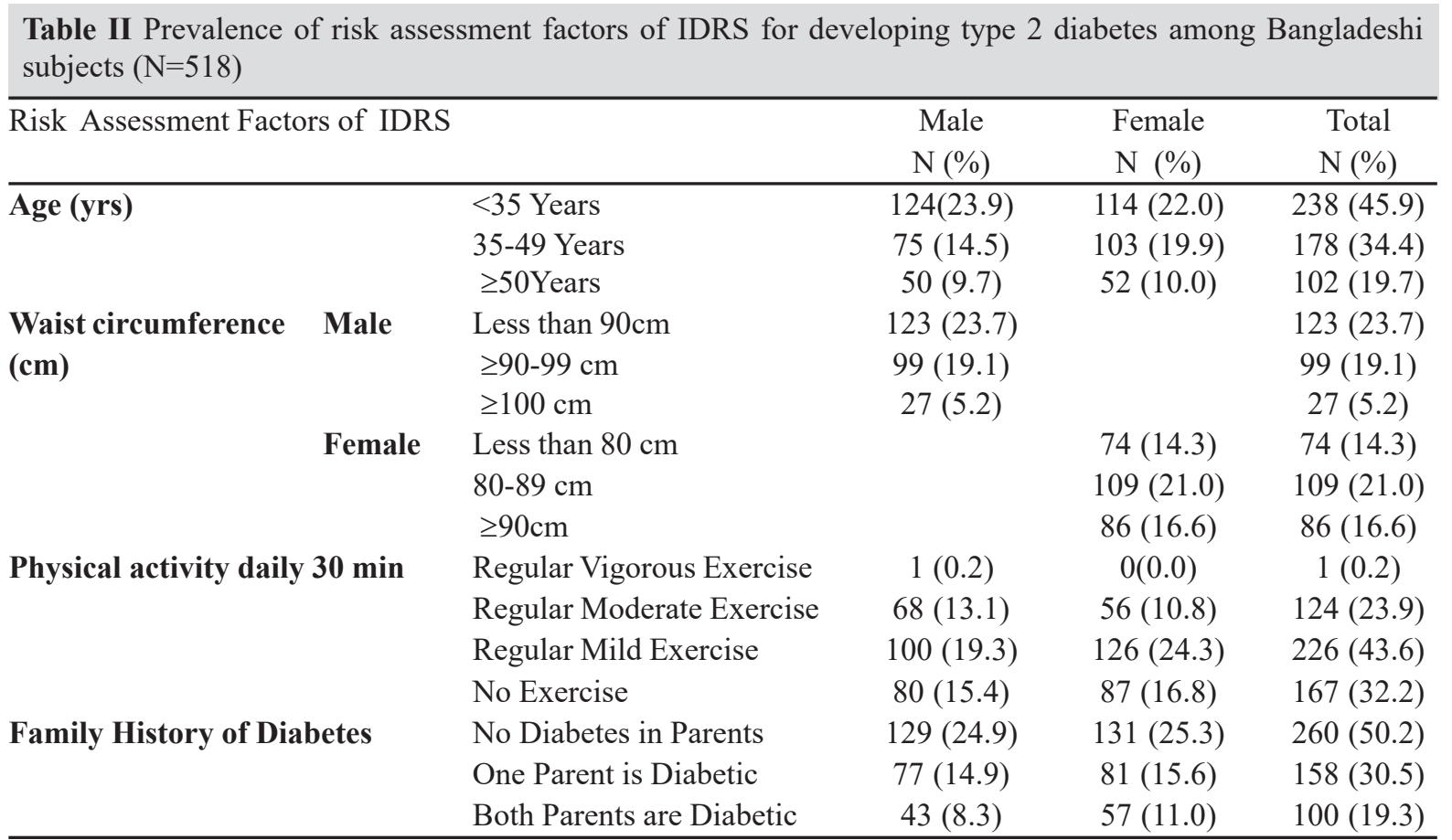

IDRS: Indian Diabetes Risk Score

Table III Association of risk factors of Indian Diabetes Risk Score among Bangladeshi adults ( $\mathrm{N}=518)$

\begin{tabular}{|c|c|c|c|c|}
\hline \multicolumn{2}{|l|}{ Risk Assessment Factors of IDRS } & $\lambda$ value & $\mathrm{df}$ & $\mathrm{p}$ value \\
\hline \multirow[t]{3}{*}{ Age (yrs) } & $<35$ Years & & & \\
\hline & 35-49 Years & 4.09 & 1 & 0.129 \\
\hline & $\geq 50$ Years & & & \\
\hline \multirow{6}{*}{$\begin{array}{l}\text { Waist circumference } \\
(\mathrm{cm})\end{array}$} & Less than $90 \mathrm{~cm}$ & 5.18 & 1 & $<0.001$ \\
\hline & $\geq 90-99 \mathrm{~cm}$ & & & \\
\hline & $\geq 100 \mathrm{~cm}$ & & & \\
\hline & Less than $80 \mathrm{~cm}$ & 5.18 & 1 & $<0.001$ \\
\hline & $80-89 \mathrm{~cm}$ & & & \\
\hline & $\geq 90 \mathrm{~cm}$ & & & \\
\hline \multirow[t]{4}{*}{ Physical activity daily $\mathbf{3 0}$ min } & Regular Vigorous Exercise & 4.68 & 1 & 0.197 \\
\hline & Regular Moderate Exercise & & & \\
\hline & Regular Mild Exercise & & & \\
\hline & No Exercise & & & \\
\hline \multirow[t]{3}{*}{ Family History of Diabetes } & No Diabetes in Parents & 1.30 & 1 & 0.520 \\
\hline & One Parent is Diabetic & & & \\
\hline & Both Parents are Diabetic & & & \\
\hline
\end{tabular}

IDRS: Indian Diabetes Risk Score 


\section{Risk assessment factors of FINDRISC}

According to Finish diabetes risk assessment tools most of the subjects were from $<45$ years age group (Male vs. Female: $33.2 \%$ vs. $35.7 \%$ ); $[\mathrm{p}=0.69$ ]. $48.8 \%$ had BMI lower than $25 \mathrm{~kg} / \mathrm{m}^{2}$ and $11.6 \%$ had BMI higher than $30 \mathrm{~kg} / \mathrm{m}^{2}$; $[\mathrm{p}=0.75] .12 .4 \%$ of female had waist circumference $>88 \mathrm{~cm}$ and $4.1 \%$ of male had waist circumference $>102 \mathrm{~cm} ;[\mathrm{p}<0.001] .69 .5 \%$ of study subjects do at least 30 minutes of daily physical activity at work or during leisure time $[\mathrm{p}=0.84]$. Most of the subjects $(62.2 \%)$ eat vegetables or fruits everyday; $[p<0.05] .22 .4 \%$ of the subjects take regular antihypertensive medication; $[\mathrm{p}=0.65]$. Among subjects, $14.7 \%$ had previous history of high blood glucose (i.e. gestational diabetes, impaired fasting glucose, or impaired glucose tolerance); $[\mathrm{p}<0.05]$. Positive family history for diabetic grandparent, aunt, uncle or first cousin was $19.3 \%$ and for diabetic parent, brother, sister or own child was $47.9 \%$; $[\mathrm{p}=0.89]$ (Table IV and V).

\begin{tabular}{|c|c|c|c|c|}
\hline \multicolumn{2}{|l|}{ Risk Assessment Factors of FINDRISC } & \multirow{2}{*}{$\begin{array}{c}\text { Male } \\
\mathrm{N}(\%) \\
172(33.2)\end{array}$} & \multirow{2}{*}{$\begin{array}{c}\begin{array}{c}\text { Female } \\
\mathrm{N}(\%)\end{array} \\
185(35.7)\end{array}$} & \multirow{2}{*}{$\begin{array}{c}\text { Total } \\
\text { N (\%) }\end{array}$} \\
\hline \multirow[t]{4}{*}{ Age (yrs) } & $<45$ Years & & & \\
\hline & 45-54 Years & $45(8.7)$ & $45(8.7)$ & $90(17.4)$ \\
\hline & 55-64 Years & $26(5.0)$ & $35(6.8)$ & $61(11.8)$ \\
\hline & $>64$ Years & $6(1.1)$ & $4(0.8)$ & $10(1.9)$ \\
\hline \multirow{3}{*}{$\begin{array}{l}\text { Family history of diabetes } \\
\text { mellitus }\end{array}$} & No & $82(15.8)$ & $88(17.0)$ & $170(32.8)$ \\
\hline & $\begin{array}{l}\text { Grand Parent, aunt, uncle, } \\
\text { or first cousin }\end{array}$ & $50(9.7)$ & $50(9.7)$ & $100(19.3)$ \\
\hline & Parent, sibling, children & $117(22.6)$ & $131(25.3)$ & $248(47.9)$ \\
\hline \multirow[t]{3}{*}{ BMI $\left(\mathrm{kg} / \mathrm{m}^{2}\right)$} & $\begin{array}{l}\text { Normal: Lower than } \\
25 \mathrm{~kg} / \mathrm{m}^{2}\end{array}$ & $118(22.8)$ & $135(26.1)$ & $253(48.8)$ \\
\hline & Over weight: $25-30 \mathrm{~kg} / \mathrm{m}^{2}$ & $100(19.3)$ & $105(20.3)$ & $205(39.6)$ \\
\hline & Obese: Higher than $30 \mathrm{~kg} / \mathrm{m}^{2}$ & $31(6.0)$ & $29(5.6)$ & $60(11.6)$ \\
\hline \multirow[t]{6}{*}{ Waist circumference (cm) } & Less than $94 \mathrm{~cm}$ & $184(35.5)$ & & $184(35.5)$ \\
\hline & $94-102 \mathrm{~cm}$ & $45(8.7)$ & & $45(8.7)$ \\
\hline & More than $102 \mathrm{~cm}$ & $21(4.1)$ & & $21(4.1)$ \\
\hline & Less than $80 \mathrm{~cm}$ & & $99(19.1)$ & $99(19.1)$ \\
\hline & $80-88 \mathrm{~cm}$ & & $106(20.5)$ & $106(20.5)$ \\
\hline & More than $88 \mathrm{~cm}$ & & $64(12.4)$ & $64(12.4)$ \\
\hline \multirow[t]{2}{*}{ Physical activity daily $30 \mathrm{~min}$} & Yes & $172(33.2)$ & $188(36.3)$ & $360(69.5)$ \\
\hline & No & $77(14.9)$ & $81(15.6)$ & $158(30.5)$ \\
\hline \multirow{2}{*}{$\begin{array}{l}\text { Vegetables, fruit or berry } \\
\text { consumption }\end{array}$} & Every day & $143(27.6)$ & $176(34.6)$ & $322(62.2)$ \\
\hline & Not every day & $106(20.5)$ & $90(17.4)$ & $196(37.8)$ \\
\hline \multirow{2}{*}{$\begin{array}{l}\text { History of hypertension with or } \\
\text { without anti-hypertensive }\end{array}$} & Yes & $58(11.2)$ & $58(11.2)$ & $116(22.4)$ \\
\hline & No & $191(36.9)$ & $211(40.7)$ & $402(77.6)$ \\
\hline \multirow{2}{*}{$\begin{array}{l}\text { History of previous high blood } \\
\text { glucose (i.e. IFG, IGT, GDM) }\end{array}$} & Yes & $23(4.4)$ & $53(10.2)$ & $76(14.7)$ \\
\hline & No & $226(43.6)$ & $216(41.7)$ & $442(85.3)$ \\
\hline
\end{tabular}

BMI: Body Mass Index; IFG: Impaired Fasting Glucose; IGT: Impaired Glucose Tolerance; GDM: Gestational Diabetes Mellitus; FINDRISC: Finnish Diabetes Risk Score 
Table V Association of risk factors of Finish Diabetes Risk Score among Bangladeshi subjects $(\mathrm{N}=518)$

\begin{tabular}{|c|c|c|c|c|}
\hline \multicolumn{2}{|l|}{ Risk Assessment Factors of FINDRISC } & \multirow{2}{*}{$\frac{\lambda \text { value }}{1.43}$} & \multirow{2}{*}{$\frac{\mathrm{df}}{3}$} & \multirow{2}{*}{$\frac{\mathrm{p}}{0.698}$} \\
\hline Age (yrs) & $<45$ Years & & & \\
\hline & 45-54 Years & & & \\
\hline & $55-65$ Years & & & \\
\hline & $>64$ Years & & & \\
\hline \multirow[t]{4}{*}{ Family history of Diabetes Mellitus } & No & 0.23 & 2 & 0.891 \\
\hline & Grand Parent, aunt, uncle, & & & \\
\hline & or first cousin & & & \\
\hline & Parent, sibling, children & & & \\
\hline \multirow[t]{3}{*}{ BMI $\left(\mathrm{kg} / \mathrm{m}^{2}\right)$} & Normal: Lower than $25 \mathrm{~kg} / \mathrm{m}^{2}$ & 0.56 & 2 & 0.756 \\
\hline & Over weight: $25-30 \mathrm{~kg} / \mathrm{m}^{2}$ & & & \\
\hline & Obese: Higher than $30 \mathrm{~kg} / \mathrm{m}^{2}$ & & & \\
\hline \multirow[t]{6}{*}{ Waist circumference(cm) } & Less than $94 \mathrm{~cm}$ & 5.14 & 3 & $<0.001$ \\
\hline & $94-102 \mathrm{~cm}$ & & & \\
\hline & More than $102 \mathrm{~cm}$ & & & \\
\hline & Less than $80 \mathrm{~cm}$ & 5.18 & 3 & $<0.001$ \\
\hline & $80-88 \mathrm{~cm}$ & & & \\
\hline & More than $88 \mathrm{~cm}$ & & & \\
\hline \multirow[t]{2}{*}{ Physical activity daily $\mathbf{3 0}$ min } & Yes & 0.04 & 1 & 0.841 \\
\hline & No & & & \\
\hline \multirow{2}{*}{$\begin{array}{l}\text { Vegetables, fruit or berry } \\
\text { consumption }\end{array}$} & Every day & 4.56 & 1 & 0.033 \\
\hline & Not every day & & & \\
\hline History of hypertensive with & No & 0.22 & 1 & 0.657 \\
\hline or without anti-hypertensive & Yes & & & \\
\hline \multirow{2}{*}{$\begin{array}{l}\text { History of previous high blood } \\
\text { glucose(i.e. IFG, IGT, GDM) }\end{array}$} & No & 11.31 & 1 & 0.001 \\
\hline & Yes & & & \\
\hline
\end{tabular}

BMI: Body mass index; FBG: fasting blood glucose; IFG: Impaired Fasting Glucose; IGT: Impaired Glucose Tolerance; GDM: Gestational Diabetes Mellitus; FINDRISC: Finnish Diabetes Risk Score. Pearson chi-square $=\lambda$ value; df: degree of freedom; $\mathrm{p}<0.05=$ significant

The IDRS predicted 10-year risk score of developing T2DM was more in female subjects than male $[\mathrm{p}<0.05]$. Among subjects, the mean $( \pm$ SD) IDRS were $45.50 \pm 17.05$ vs. $52.23 \pm 19.26$ (male vs. female) (Table I).

According to IDRS system, $37.8 \%$ of the subjects (male vs. female: $14.8 \%$ vs. $23.0 \%$ ) had high risk score for developing diabetes. While $48.8 \%$ had moderate risk (male vs. female: $25.5 \%$ vs. $23.4 \%$ ) and $13.3 \%$ had low risk (male vs. female: $7.7 \%$ vs. $5.6 \%$ ); $[p<0.05]$ (Figure 1).

The FINDRISC predicted 10-year risk score of developing T2DM was more in female subjects than male; $[\mathrm{p}<0.05]$. Among subjects, the mean $( \pm \mathrm{SD})$ FINDRISC were $7.33 \pm 4.31$ vs. $8.86 \pm 5.22$ (Male vs. Female) (Table I). 


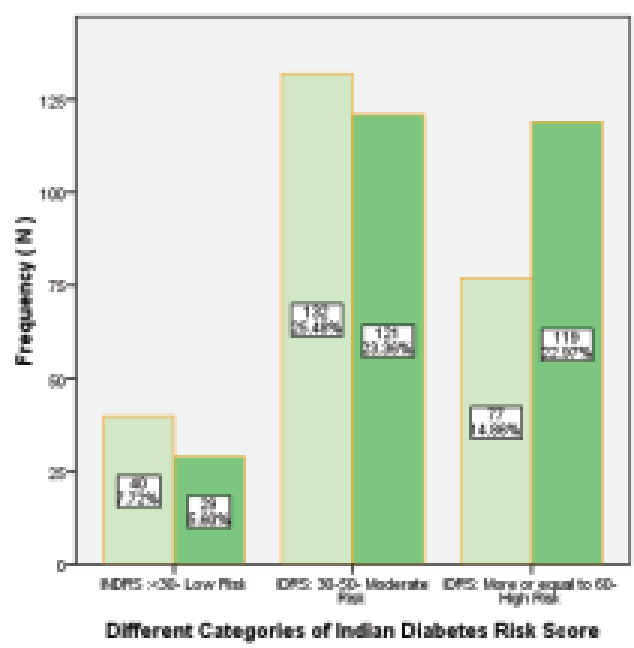

Figure 1 Distribution of study subjects according to different categories of IDRS $(\mathrm{N}=518)$

According to FINDRISC tools, $36.5 \%$ of the subjects (male vs. female: $16.2 \%$ vs. $20.3 \%$ ) had slightly elevated diabetes risk score (DRS). While 14.3\% had moderate DRS (Male vs. Female: $6.4 \%$ vs. $7.9 \%$ ) and $8.3 \%$ had high DRS (male vs. female: $1.9 \%$ vs.6.4\%). Only $0.4 \%$ had very high risk score; $[p<0.05]$ (Figure2).

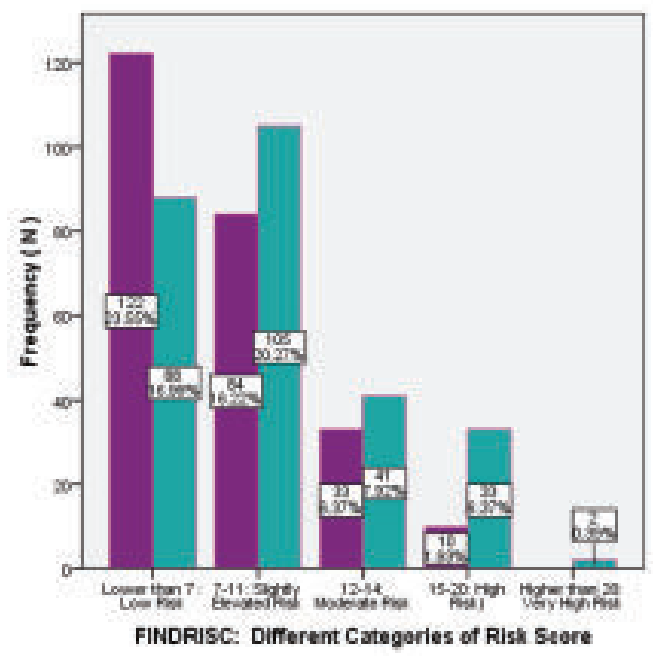

Figure 2 Different categories of Finish diabetes risk score among Bangladeshi subjects $(\mathrm{N}=518)$

\section{Comparison between two risk scores}

In accordance with IDRS tool, $37.8 \%$ of the subjects were in high risk category for developing diabetes (male vs. female: $14.8 \%$ vs. $23.0 \%$ ); [ $<<0.05]$ (Figure 1). However, the predicted risk of FINDRISC tool for the same category was lower (8.3\%; male vs. female: $1.9 \%$ vs.6.4\%); [p<0.05] (Figure 2).

\section{Discussion}

The systematic review ${ }^{34}$ shows that the predictive ability of diabetes risk scores, which have been developed in populations of varying ethnic backgrounds, differs considerably between populations. Although collecting data from a questionnaire is likely less costly and more acceptable than methods of screening involving biochemical measures such as blood glucose; but difficulties in distributing questionnaires, the time required to complete them, the complexity of computing the results, issues related to misreporting (reporting bias), and unavailability of some required information may hamper their population-wide application. Furthermore, these risk scores focus mainly on nonmodifiable risk factors such as age and family history or on the consequences of adverse health behaviors such as high body mass index and waist circumferences, high blood pressure, and medication use. The feasibility of implementing any screening model will depend on the availability and completeness of the required risk factor data. $^{34}$

This study examined whether the adoption of two different validated risk-assessment tools would alter an individual's predicted risk of type 2 diabetes. The risk assessment tools were chosen in this study primarily because they feature in the NICE guidance, ${ }^{35}$ and also have common risk variables that make comparisons feasible.

The main findings from this study demonstrated that the risk of individual developing type 2 diabetes was dependent on which risk-assessment tool was used. It was observed that $37.8 \%$ of subjects were predicted to be in the high-risk category when the Indian Diabetes Risk Score was used whereas Finish Diabetes Risk Score declared $8.3 \%$ for the same category. These data highlight the inconsistency of the predictive value of these different risk assessment tools.

\section{Conclusion}

The results of this study indicate that the prevalence of participants at risk for developing type 2 diabetes varies considerably according to the scoring system used. The adoption of a different valid risk assessment tool can alter the predicted risk of an individual and caution should be used to identify those individuals who really are at high risk of type 2 diabetes. 


\section{Limitations}

This study is limited by the cross-sectional design and is not causal or effect study or measure of temporal changes. Validation of the risk assessment with a large sample size in different populations would have enhanced the generalizability of the results.

Conflicts of interest: Nothing to declare.

\section{References}

1. American Diabetes Association. Standards of medical care in diabetes: 2009. Diabetes Care 2009; 32(Suppl. 1):S13S61

2. Mohiuddin AK. Diabetes Fact: Bangladesh Perspective. International Journal of Diabetes Research 2019; 2(1):14-20.

3. International Diabetes Federation. Diabetes prevalence, Geographical profile. IDF diabetes Atlas 9th edition, 2019.

4. Knowler WC, Barrett-Connor E, Fowler SE, Hamman RF, Lachin JM, Walker EA, et al. Diabetes Prevention Program Research Group. Reduction in the incidence of type2 diabetes with lifestyle intervention or metformin. N Engl J Med 2002; 346:393-403.

5. Kahn HS, Cheng YJ, Thompson TJ, Imperatore G, Gregg EW. Two risk-scoring systems for predicting incident diabetes mellitus in U.S. adults age 45 to 64 years. Ann Intern Med 2009; 150:741-51.

6. Wilson PW, Meigs JB, Sullivan L, Fox CS, Nathan DM, D'Agostino RB Sr. Prediction of incident diabetes mellitus in middle-aged adults: the Framingham Offspring Study. Arch Intern Med 2007; 167: 1068-74.

7. Griffin SJ, Little PS, Hales CN, Kinmonth AL, Wareham NJ. Diabetes risk score: towards earlier detection of type 2 diabetes in general practice. Diabetes Metab Res Rev 2000; 16:16471.

8. Balkau B, Lange C, Fezeu L, Tichet J, de Lauzon-Guillain B, Czernichow S, et al. Predicting diabetes: clinical, biological, and genetic approaches: data from the Epidemiological Study on the Insulin Resistance Syndrome (DESIR). Diabetes Care 2008; 31:2056-61.

9. Diabète de type 2: quelestvotrerisque? [Internet], 2011.(Available from http://www.diabetesgesellschaft.ch/fr/ informations/test-diabete/. Accessed 26 May 2011).

10. Findrisk ("finde das risiko") fragebogen: optimierte deutsche version [Internet], 2011. Available from www.diabetesheute.de. Accessed 27 May 2011.

11. Mann DM, Bertoni AG, Shimbo D, Carnethon MR, Chen H, Jenny NS, et al. Comparative validity of 3 diabetes mellitus risk prediction scoring models in amultiethnic US cohort: the Multi-Ethnic Study of Atherosclerosis. Am J Epidemiol 2010; 171:980-88.

12. Hense HW, Schulte H, Löwel H, Assmann G, Keil U. Framingham risk function ver estimates risk of coronary heart disease in men and women from Germany: results from the MONICA Augsburg and the PROCAM cohorts. Eur Heart J 2003; 24:937-45.

13. Franciosi M, De Berardis G, Rossi MC, Sacco M, Belfiglio $\mathrm{M}$, Pellegrini $\mathrm{F}$, et al. Use of the diabetes risk score for opportunistic screening of undiagnosed diabetes and impaired glucose tolerance: the IGLOO (Impaired Glucose Tolerance and Long-Term Outcomes Observational) study. Diabetes Care 2005; 28(5): 1187-94.

14. Herman WH, Smith PJ, Thompson TJ, Engelgau M, Aubert R. A new and simple questionnaire to identify people at increased risk for undiagnosed diabetes.Diabetes Care1995; 18(3): 382-87.

15. Baan CA, Ruige JB, Stolk RP, Witteman JC, Dekker JM, Heine RJ, Feskens EJ. Performance of a predictive model to identify undiagnosed diabetes in a health care setting. Diabetes Care 1999; 22(2): 213-19.

16. Griffin SJ, Little PS, Hales CN, Kinmonth AL, Wareham NJ. Diabetes risk score: towards earlier detection of type 2 diabetes in general practice. Diabetes Metab Res Rev2000; 16(3): 16471.

17. Lindstrom J, Tuomilehto J. The diabetes risk score: a practical tool to predict type 2 diabetes risk. Diabetes Care 2003; 26: 725-31.

18. Glumer C, Jorgensen T, Borch-Johnsen K. Targeted screening for undiagnosed diabetes reduces the number of diagnostic tests. Diabet Med 2004; 21: 874-80.

19. Mohan V, Deepa R, Deepa M, Somannavar S, Datta M. A simplified Indian Diabetes Risk Score for screening for undiagnosed diabetic subjects. J Assoc of Physicians India 2005; 53: 759-63.

20. Aekplakorn W, Bunnag P, Woodward M, Sritara P, Cheepudomwit S, Yamwong S, et al. A risk score for predicting incident diabetes in the Thai Population. Diabetes Care 2006; 29: $1872-77$.

21. Al-LawatiJ A, Tuomilehto J. Diabetes risk scores in Oman: a tool to identify prevalent type 2 diabetes among Arabs of the Middle East. Diabetes Res Clin Pract 2007; 77(3): 438-44.

22. National Institute for Health and Care Excellence. Preventing type 2 diabetes: risk identification and interventions for individuals at high risk. NICE public health guidance 38 2012, London.

23. Latchan Z, Seereeram R, Kamalodeen A, Sanchez S, Deonarine U, Sinanan R, et al. TRAQ-D (Trinidad Risk Assessment Questionnaire for Type 2 Diabetes Mellitus): a cheap, reliable, non-invasive screening tool for diabetes. $\mathrm{Br} \mathrm{J}$ Diabetes Vasc Dis 2010; 10: 187-92.

24. Saaristo T, Peltonen M, Keinänen-Kiukaanniemi S, Vanhala M, Saltevo J, Niskanen L, et al. Type 2 diabetes prevention programme in Finland: FIN-D2D. Int J Circumpolar Health 2007; 66(2): 101-12. 
25. Schwarz PE, Lindstrom J, Kissimova-Scarbeck K, Szybinski Z, Barengo NC, Peltonen M, et al. DE-PLAN project. The European perspective of type 2 diabetes prevention: diabetes in Europe - prevention using lifestyle, physical activity and nutritional intervention (DE-PLAN) project. Exp Clin Endocrinol Diab 2008; 116(3): 167-72.

26. Schwarz PEH, Li J, Reimann M, Schutte AE, Bergmann A, Hanefeld M, et al. The Finnish Diabetes Risk Score is associated with insulin resistance and progres-sion towards type 2 diabetes. J Clin Endocrinol Metab 2009; 94: 920-26.

27. Bergmann A, Li J, Wang L, Schulze J, Bornstein SR, Schwarz PE. A simplified Finnish dia-betes risk score to predict type 2 diabetes risks and disease evolution in a German population. Horm Metab Res 2007; 39(9): 677-82.

28. Allsema M, Feskens EJ, Bakker SJ, Miguel MG, Núria IJ, Ramon E, et al. Finnish questionnaire reasonably good predictor of the incidence of diabetes in The Netherlands. Ned TijdschrGeneeskd2008; 152(44): 2418-24.

29. Sharma KM, Ranjani H, Nguyen H, Shetty S, Datta M, Narayan KM, et al. Indian Diabetes Risk Score helps to distinguish type 2 from non-type 2 diabetes mellitus (GDRC3). J Diabetes Sci Technol Mar 2011; 5(2):419-25
30. Smith Liz. New AHA recommendations for blood pressure measurement: American Heart Association Practice Guidelines. Am Fam Physician 2005; 72(7): 1391-98.

31. Mohan V, Sandeep S, Deepa M, Gokulakrishnan K, Datta M, Deepa R. A diabetes risk score helps identify metabolic syndrome and cardiovascular risk in Indians - the Chennai Urban Rural Epidemiology Study (CURES-38). Diabetes, obesity \& metabolism May 2007; 9(3):337-43.

32. Mohan V, Deepa M, Farooq S, Narayan KM, Datta M, Deepa R. Anthropometric cut points for identification of cardiometabolic risk factors in an urban Asian Indian population. Metabolism Jul 2007; 56(7):961-68.

33. Mohan V, Deepa M, Farooq S, Prabhakaran D, Reddy KS. Surveillance for risk factors of cardiovascular disease among an industrial population in southern India.Natl Med J India Jan-Feb 2008; 21(1):8-13.

34. Herman WH. Predicting risk for diabetes: choosing (or building) the right model. Ann Intern Med 2009; 150(11): 812-14.

35. National Institute for Health and Care Excellence. Preventing type 2 diabetes: risk identification and interventions for individuals at high risk. London: NICE, 2012. http:// www.nice.org.uk/guidance/ph38 (accessed 24 Sep 2015). 